\title{
Representaciones Sintácticas de la Estructura de Rasgos
}

\author{
Tlahuilli Salazar Reyes
}

Universidad Autónoma Metropolitana - Iztapalapa

Maestría en Humanidades, línea Lingüística.

Asesor: Dr. José Lema Labadie 
Índice de contenidos

0.1 Lista de abreviaciones

1. Introducción

2. Sincretismo

2.1. Caso Abstracto

2.2. Definición

2.3. Principio de Contigüidad (PC)

2.3.1. Problemas al PC

2.4. Violación al PC en español

3. Leísmo

3.1. Definición

3.2. Leísmo como sincretismo

3.3. Sistema pronominal del español

3.4. Tipos de leísmo

3.5. Propuestas de análisis

4. Construcciones de Doble Objeto

4.1. Transitividad

4.2. Construcciones Ditransitivas

4.3. Marcación Diferencial de Caso

4.4. Argumento Dativo

4.4.1. Tipos de Aplicativa

4.5. Caso Profundo

5. Consecuencias 
Representaciones Sintácticas

5.1. CDO en español

5.2. Larson

6. Conclusiones 


\section{Lista de abreviaciones}

\begin{tabular}{|c|c|}
\hline A & Agente \\
\hline$A C$ & Acusativo \\
\hline APL & Aplicativa \\
\hline ATR & Agente Tema Receptor \\
\hline CDO & Construcción de Doble Objeto \\
\hline COM & Comitativo \\
\hline CM & Caso Morfológico \\
\hline DAT & Dativo \\
\hline DOM & Differential Object Marking \\
\hline DOC & Double Object Construction \\
\hline GEN & Genitivo \\
\hline HSA & Hipótesis de Sincretismo Adyacente \\
\hline MDO & Marcación Diferencial de Objeto \\
\hline NOM & Nominativo \\
\hline 0 & Objeto \\
\hline $\mathrm{OBL}$ & Oblicuo \\
\hline OD & Objeto Directo \\
\hline OI & Objeto Indirecto \\
\hline $\mathrm{OP}$ & Objeto Primario \\
\hline OS & Objeto Secundario \\
\hline$P$ & Paciente \\
\hline
\end{tabular}


Representaciones Sintácticas

$\begin{array}{ll}\text { PC } & \text { Principio de Contigüidad } \\ \text { PERF } & \text { Perfectivo } \\ \text { PRES } & \text { Presente } \\ \text { POS } & \text { Posesivo } \\ \text { R } & \text { Receptor } \\ \text { S } & \text { Sujeto } \\ \text { SG } & \text { Singular } \\ \text { T } & \text { Tema } \\ \text { V } & \text { Verbo }\end{array}$


The structure of language requires that the meanings of grammatical units -just like all other linguistic elements- be studied not in isolation but within the system to which they belong.

(Jakobson) On Language

\section{INTRODUCCIÓN}

Muchos de los trabajos lingüísticos han estado restringidos al estudio de alguna estructura, una secuencia, el uso de alguna forma específica $o$ de un fenómeno en particular. Las explicaciones a las que se llega en la mayoría de los casos resultan de utilidad únicamente para ahondar en el estudio del tema en cuestión y las conclusiones sirven a quienes pretenden tomarlas como punto de partida o para aquellos que desean rebatirlas. Suele haber más de una explicación para determinados fenómenos debido a la naturaleza excluyente con que se abordan los temas de estudio y comúnmente encontramos diferentes explicaciones a fenómenos similares que, ubicados en un marco más amplio, parecen incompatibles, ya sea por sus supuestos teóricos, su metodología o simplemente por la manera centralista en que han sido llevados a cabo.

En el presente trabajo abordaré tres temas que, desde mi punto de vista, pueden (y deberían) ser analizados 
conjuntamente. Todos los fenómenos estudiados están unificados por un punto de encuentro: la(s) estructura(s) de objeto(s) en español (construcciones [di]transitivas), mismas que están caracterizadas por un comportamiento aparentemente inesperado 0 inestable de los elementos fonéticos correspondientes a los Casos acusativo y dativo.

\section{SINCRETISMO}

El primer fenómeno tiene que ver con el uso de preposiciones en lenguas hermanas y las diferencias que presentan.

Francés/Italiano
(1)
a. Le livre
est
à Marie.
b. Il libro
es
a Maria
El libro
ser.PRES.3SG
Marie.GEN
(2) a. Pierre a donné un livre à Marie.
b. Pietro ha dato un libro a Maria.
Dar.PERF un libro Marie.DAT

En (1) y (2) vemos como la preposición que introduce los Casos genitivo y dativo (à/a) es la misma, es decir, la misma forma con dos funciones diferentes, dos formas sincréticas. El sincretismo no es algo raro sino relativamente frecuente según Jakobson (1936), quien define el fenómeno como la neutralización de la oposición de Caso en ciertas formas morfológicas. 
Para poder hablar de sincretismo dentro de este trabajo, una aclaración resulta pertinente. No me refiero a la noción tradicional de Caso: el morfológico. Sino a la noción abstracta con base en que el Caso funciona como un sistema de marcación de sustantivos por medio del cual podemos identificar la función que estos desempeñan dentro de las oraciones. Sigo el pensamiento de Pesetsky y Torrego (2001), que el lenguaje está gobernado por reglas abstractas y que es hacia allá a donde debemos encaminarnos.

\section{Español}
(3) a. *El libro es a María.
b. Pedro le dio un libro a María.

En español, una lengua emparentada con el francés y el italiano, el empleo de la preposición a para introducir genitivo es agramatical, como podemos observar en (3). ${ }^{1}$ La ausencia del sincretismo entre las formas de genitivo y dativo es interesante por sí misma. Sin embargo, resulta más interesante aún que el fenómeno del sincretismo sí se encuentre en la lengua pero con diferentes Casos.
(4) a. Pedro vio a María.
b. Pedro le dio un libro a María.

\footnotetext{
${ }^{1}$ La preposición de genitivo en la lengua española es de. El libro es de María es la forma correcta.
} 
Vemos en (4) que la marca de acusativo (OD) a Maria coincide con la de dativo (OI) a María. Este tipo de sincretismo no ocurre un francés o italiano. En estas lenguas la preposición solo puede introducir dativo pero nunca acusativo.

Como se mencionó antes, la neutralización de la oposición de Caso no es extraña pero de acuerdo con Caha (2009) existe una jerarquía universal y una restricción a la aparición de formas sincréticas. Según su propuesta las formas sincréticas solo pueden aparecer si son adyacentes dentro de una escala (acusativo-genitivo, por ejemplo) y nunca entre casos separados (*nominativo-genitivo). El sistema de contigüidad que presenta es el siguiente:

nominativo - acusativo - genitivo - dativo - instrumental - comitativo

Tomando en cuenta esta propuesta podemos dar cuenta del sincretismo esperado en diferentes lenguas, como las formas pronominales de segunda persona nominativo y acusativo en inglés, por ejemplo, la forma you de sujeto/objeto no viola la restricción de adyacencia. 0 el fenómeno de sincretismo del francés y el italiano, donde las formas sincréticas que se presentan son entre Casos adyacentes (genitivo y dativo) y, por lo tanto, no hay violación al sistema.

Existe un sinnúmero de casos que podrían ejemplificar la propuesta de Caha pero, en este trabajo me enfocaré en el 
sincretismo, aparentemente ilegal, del español entre formas no adyacentes. La forma sincrética $a$.

El uso de $a$, ya sea como preposición o marca de caso es sin duda uno de los fenómenos más interesantes del español. Sus diferentes significados y la variedad de estructuras en que se usa la hacen un elemento que se ha tomado en cuenta en muchos y muy diferentes estudios lingüísticos. Desde su forma claramente preposicional con sus diversos significados (direccionalidad, estado, manera, periodicidad) que se muestran en (5), sus usos como parte de perífrasis de futuro o en un tipo de estructura de imperativo (6) hasta el problema de la a como marca de objeto directo e indirecto (7), entre otros, es este un elemento que ha capturado la atención de muchos estudiosos y ha sido el tema principal de muchos trabajos.

(5) a. Pedro va a su casa.

b. El cine está a la derecha.

c. Nos fuimos a caballo.

d. La medicina se toma tres veces al día.

(6) a. Voy a comprar una bicicleta la próxima semana.

b. ¡A comer!

(7) a. Pedro vio a María.

b. Pedro le trajo flores a María. 
En el presente trabajo abordaré únicamente la a que introduce los objetos directo e indirecto. Es precisamente con esta función donde surgen algunas de las complicaciones dentro del sistema de contigüidad propuesto por Caha, en el cual se expone la aparente imposibilidad de tener formas sincréticas con Casos no adyacentes.

El objeto directo en español no va introducido por preposición o marca alguna, del mismo modo que en francés o italiano.

(8) a. Pedro compró flores.

b. Pierre a acheté des fleurs.

c. Pietro a comprato fiori.

Como podemos observar en (8), flores (fleurs o fiori) cumple la función de OD y no requiere de ninguna marca para ello. El OD típicamente se encuentre inmediatamente después del verbo transitivo $y$, a diferencia del sujeto, no presenta concordancia con el verbo.

Sin embrago, cuando el OD es humano es necesaria la marca (o preposición) a que lo introduzca y su ausencia resulta agramatical, lo cual es diferente en las otras dos lenguas romance. En francés o italiano el OD no lleva marca.

(9) a. Pedro vio a María.

b. *Pedro vio María. 
c. Pierre a vu Maria.

d. Pietro ha visto Maria.

A diferencia del OD inanimado (no humano), en español el OD que presenta los rasgos [+animado] y [+definido] se marca con $a$. Como en (9a) donde María (que es el OD del verbo ver) presenta la marca. La misma marca que, como se muestra en (10b), se utiliza para el OI (típicamente humano).

(10) a. Pedro vio a María.

b. Pedro le dio un libro a María.

Esta marcación diferenciada de OD (MDO) en español da como resultado una aparente violación al sistema de contigüidad propuesto por Caha. Violación que no es extraña, empero, y de la cual se muestran datos a continuación.

(11) nórdico antiguo, islandés y faroés

Old Norse Iversen (1974)

\begin{tabular}{|c|c|c|c|c|}
\hline & a-stem M & a-stem $\mathrm{N}$ & o-stem F & an-stem M \\
\hline NOM & arm-r & land- $\varnothing$ & fjọðr- $\varnothing$ & grann-i \\
\hline ACC & arm- $\varnothing$ & land- $\varnothing$ & fjọðr- $\emptyset$ & grann-a \\
\hline GEN & arm-s & land-s & fjọðr-a & grann-a \\
\hline \multirow[t]{2}{*}{ DAT } & arm-i & land-i & fjọðr- $\emptyset$ & grann-a \\
\hline & 'arm' & 'land' & 'feather' & 'neighbor' \\
\hline \multicolumn{5}{|c|}{ Modern Icelandic } \\
\hline & a-stem M & a-stem N & o-stem F & on-stem \\
\hline NOM & arm-ur & land- $\varnothing$ & drottning- $\varnothing$ & tung-a \\
\hline ACC & arm- $\varnothing$ & land- $\varnothing$ & drottning-u & tung-u \\
\hline GEN & arm-s & land-s & drottning-ar & tung-u \\
\hline \multirow[t]{2}{*}{ DAT } & arm-i & land-i & drottning-u & tung-u \\
\hline & 'arm’ & 'land' & ‘queen' & 'tongue' \\
\hline \multicolumn{5}{|c|}{ Faroese Práinsson et al. (2004) } \\
\hline & Mclass 1 & $\mathrm{~N}$ class $1 \mathrm{a}$ & F class $1 \mathrm{a}$ & F class 5 \\
\hline NOM & dag-ur & barn- $\varnothing$ & vørr- $\emptyset$ & tung-a \\
\hline ACC & dag- $\varnothing$ & barn- $\emptyset$ & vørr- $\emptyset$ & tung-u \\
\hline GEN & (dag-s) & (barn-s) & (varr-ar) & (tung-u) \\
\hline \multirow[t]{2}{*}{ DAT } & deg-i & barn-i & vørr- $\varnothing$ & tung-u \\
\hline & 'day' & 'child' & ‘lip’ & tongue' \\
\hline
\end{tabular}


De acuerdo con Rúnar, en nórdico antiguo, islandés y faroés se presenta el mismo tipo de sincretismo, aparentemente ilegal, que en español. Es decir, existen formas sincréticas con Casos acusativo y dativo sin que se observe en genitivo. Rúnar propone una versión débil de Caso que con un solo reordenamiento en el sistema de contigüidad da cuenta del fenómeno en las lenguas del oeste nórdico y de algunos problemas que Caha mismo presenta en su texto. Posiblemente sea el Caso Débil de utilidad también en el caso de la lengua española que se asemeja a las lenguas trabajadas por Rúnar en lo que respecta a este fenómeno.

\section{LEÍSMO}

La variación del uso de los pronombres átonos de tercera persona en la lengua española a lo largo del tiempo del que se cuenta con documentos "ocasiona la convivencia de usos que se atienen al canon heredado del latín y usos innovadores conocidos como leísmo, laísmo y loísmo.” (Flores). Es precisamente el leísmo el que se encuentra en el ámbito de esta investigación.

La Real Academia Española define el leísmo como "el uso impropio de $L e(s)$ en función de complemento directo, en lugar de Lo (para el masculino singular o neutro), Los (para el masculino plural) y $L a(s)$ (para el femenino), que son las formas a las que corresponde etimológicamente ejercer esa función.”

Aquí los ejemplos que presenta Fernández-Ordoñez 
(12) a. ¿Conoces a Juan? Sí, le conozco hace tiempo.

b. ¿Sabes dónde está mi libro? No, no le he visto por aquí.

c. Esta tarde voy a recoger a los niños del colegio y les levaré al parque.

d. Fui a buscar los discos que querías y les encontré en la tienda de abajo.

e. A María hace tiempo que no le veo.

f. Aquí no hay monjas. En la guerra les mataron a todas

Los ejemplos de (12) muestran el uso inesperado del pronombre dativo le (de objeto indirecto) en contextos en los cuales se espera el uso de las formas pronominales de acusativo Lo, La, Los y las. En todos ellos se hace uso de verbos transitivos por lo cual el uso de pronombres de objeto indirecto se aleja de la prescripción.

El fenómeno del leísmo es un tema ampliamente estudiado desde hace más de un siglo ${ }^{2}$. Tiene incluso marcadas y diferentes maneras por las cuales se ha acercado a su estudio. Hipótesis que toman diferentes posturas frente al fenómeno y que, como es de esperarse, llegan a diferentes explicaciones.

Las llamadas hipótesis tradicionales (Cuervo, Fernández Ramírez, Lapesa) toman como eje central la postulación de la

\footnotetext{
${ }^{2}$ Fuentes
} 
eliminación del Caso a favor del género, la analogía por extensión del sincretismo de las formas pronominales de primera y segunda personas así como el deseo de conservación de la distinción entre masculino y neutro.

Frente a las limitaciones para explicar adecuadamente el conjunto de fenómenos (leísmo, laísmo y loísmo) que aseguran autores más recientes, surgen hipótesis más modernas. Estas presentan un cambio radical en el estudio del fenómeno ya que ponen especial énfasis en aspectos sociolingüísticos y geográficos y no solo en los puramente gramaticales y funcionales. Estas "nuevas hipótesis" llaman a reconsiderar la metodología de recolección de datos y a tomar en cuenta el dialecto del que provengan. Asimismo señalan la imperiosa necesidad de considerar no únicamente la lengua escrita ya que esta se encuentra, por su propia naturaleza, mucho más cerca de la norma.

(13) Sistema pronominal

OD OI

1 SG Me $\quad$ Me

2 SG Te $\quad$ Te

3 SG lo / la Le

$1 \mathrm{PL}$ Nos Nos

$3 \mathrm{PL}$ los / las Les 
Como se puede ver, la aparente violación al sistema de contigüidad por el sincretismo encontrado en español entre marcas de acusativo y dativo así como el fenómeno del leísmo se encuentran relacionados con respecto al Caso. Es decir, los fenómenos se encuentran en el uso de OD y OI, acusativo y dativo, respectivamente. No obstante, existe otro fenómeno que se encuentra dentro del espectro de interés del presente trabajo: El uso de le con función no pronominal.

Le con incorporación preposicional

En español se da un fenómeno que no sucede en otras lenguas romance (francés o italiano, por ejemplo). Se trata del uso no pronominal de Le, como se muestra a continuación:
(14) a. Pedro le mandó un libro a Gaby.
b. Pedro le puso azúcar al Café.
c. Pedro le lavó el carro a Valeria
d. Pablo les preparó sándwiches a todos.

Los ejemplos anteriores fueron tomados de Cuervo (2003) y son los que utiliza para ejemplificar la construcción de doble objeto $(C D O)$ en español con aplicativa como núcleo de frase, que sirve para introducir argumentos al complejo verbal.

En (14) podemos ver el uso de le en CDO con verbos originalmente transitivos (que toman solo dos argumentos, un sujeto y un OD) a las cuales se les agrega el argumento 
"dativo". Esto se logra mendiante la aplicación del clítico que permite la incorporación del tercer argumento que el verbo no exige pero que puede añadirse.

A primera vista podría pensarse que la construcción es indirectiva, como se supone es común con verbos ditransitivos. Sin embargo, los verbos de tres argumentos admiten las construcciones sin el uso del clítico dativo, lo cual en el caso de las CDO da como resultado construcciones agramaticales (o al menos extrañas para el hablante nativo).

(15) a. Pedro dio un libro a María b. Pedro le $e_{i}$ dio un libro a María .

(16) a. Pedro lavó el carro de María.

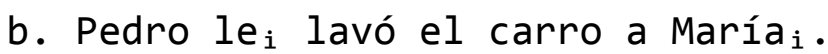
c. *Pedro lavó el carro a María.

En (15) vemos que las oraciones con verbos ditransitivos admiten los dos tipos de construcción, con y sin clítico dativo (aunque se prefieran las que lo llevan) y, por el contrario, las oraciones con verbos transitivos admiten solo las construcciones tipo DOC. Cuervo asegura que las estructuras que no presentan el clítico son de tipo indirectivas, es decir, que el oI se introduce por la preposición a, mientras que las que cuentan con el clítico son $\mathrm{CDO}$, sin preposiciones. 
Un elemento más que debemos considerar en las CDO es la posibilidad, poco mencionada, de tener construcciones donde el clítico y la frase dativa (en el sentido de Casos profundos que describe Fillmore) no concuerdan.

(17) Pedro le compró libros a sus hijos. 
...el lenguaje está gobernado por reglas abstractas y es hacia allá a donde debemos encaminarnos.

Pesetsky y Torrego (2001)

\section{SINCRETISMO}

Todas las oraciones en las diversas lenguas se componen por un complejo verbal y al menos un argumento. Un argumento es un complemento o un constituyente que el verbo exige para expresar su significado. Dependiendo del significado del verbo en cuestión la oración requerirá unos o más argumentos para satisfacer su estructura semántica. Es decir, el verbo por su significado requiere una cantidad mínima de participantes para su adecuada interpretación.

Los verbos que exigen dos participantes se conocen como transitivos $y$, en lenguas como el español, suelen realizarse como sujeto y objeto directo. Existen también verbos ditransitivos que requieren (además de los argumentos anteriores) un segundo objeto, que se conoce como objeto indirecto.

Todo argumento de un verbo dentro de una oración debe estar ligado a un rasgo de Caso $\mathrm{y}$, por lo tanto, cumple una función sintáctica (Sujeto u Objeto, por ejemplo). La forma en que los argumentos se manifiestan en la oración suele ser indicador del Caso que presentan. Es decir, que dependiendo del Caso (y la 
función que realizan en la oración) es la forma en que aparecen los argumentos.

\section{CASO ABSTRACTO}

Tradicionalmente la noción de caso se empleaba para referirse al uso ligado a la representación morfológica de las funciones sintácticas desempeñadas por los argumentos dentro de la oración.

Sin embargo, dentro del trabajo realizado dentro del marco de Principios y Parámetros (Chomsky 1981), el Caso (en una definición mucho más abarcadora) es una noción abstracta propia de un módulo principiado de la gramática. Todo argumento nucleado por un sustantivo fonéticamente explícito debe tener Caso, y este puede asumir diversas formas morfológicas o sintácticas, entre ellas el Caso Morfológico (CM).

En español, por ejemplo, que no es una lengua de $\mathrm{CM}^{3}$, el Caso que presentan los argumentos se expresa por mecanismos no morfológicos. El Caso nominativo (NOM) se expresa mediante la concordancia. Es el argumento que concuerda con el verbo en número y persona, y cumple la función de sujeto (S). El argumento con Caso acusativo ( $A C$ ) no se encuentra marcado, mas que bajo determinadas circunstancias.

(18) Juan escribió las cartas.

\footnotetext{
${ }^{3}$ La lengua española, a diferencia de latín (o cualquier otra lengua de CM) no presenta afijos que evidencien el Caso que presentan los argumentos.
} 
En (18) se observa la concordancia entre la señora (3SG) y la flexión del verbo escribir (PERF.3SG) que no se da con las cartas $(3 \mathrm{PL})$. Entonces reconocemos a Juan con función de sujeto (NOM) y Las cartas, que no presentan ninguna marca, como objeto $(A C)$.

Existen otras formas de identificar el Caso que presentan los argumentos verbales. Por ejemplo, la lengua inglesa que morfológicamente solo presenta diferencias en los pronombres de S y 0 (NOM y ACC, respectivamente) tiene un sistema de marcación de Caso Estructural, por el orden en que aparecen las palabras. Es decir, la posición de los argumentos con respecto al verbo de la oración es la que nos permite distinguir las diferentes funciones que desempeñan las FN, como en (3).

$$
\begin{aligned}
& \text { (19) My } \quad \text { brother bought the newspaper. } \\
& \text { POS.1SG hermano.NOM comprar.PERF el periódico.ACC } \\
& \text { 'Mi hermano compró el periódico' }
\end{aligned}
$$

El inglés es una lengua de orden estricto SVO. El argumento con Caso NOM se muestra siempre antes del verbo mientras que el argumento con Caso AC aparece después del verbo. En (19) ninguno de los argumentos del verbo presenta morfología de Caso pero, a pesar de ello este se muestra por el orden. Entonces, sabemos que el argumento my brother tiene Caso NOM y the newspaper, Caso $\mathrm{AC}$.

Como mencionamos anteriormente, el Caso es un elemento abstracto de la lengua que no se marca únicamente mediante la 
concordancia o el orden. Existen lenguas que marcan Caso de otras maneras.

Tomemos el latín o el alemán como ejemplo. En la lengua clásica el Caso funciona como un sistema de marcación de sustantivos por medio del cual podemos identificar la función que estos desempeñan dentro de las oraciones.

$$
\begin{aligned}
& \text { (20) Dominus equum cōnsulī dedit } \\
& \text { dueño.NOM caballo.AC cónsul.DAT dar.PERF.3SG } \\
& \text { "El dueño le dio el caballo al cónsul" }
\end{aligned}
$$

Todos los argumentos del verbo dar (dominus, equum $y$ cōnsulī) tienen Caso (NOM, AC y dativo [DAT], respectivamente) y este se manifiesta con diferentes flexiones en el sustantivo, lo cual nos ayuda a distinguir las funciones gramaticales que desempeñan en la oración.

Las lenguas que marcan morfológicamente el Caso, como el latín, parecen presentar la tendencia al orden SOV. Aunque no necesariamente es así, ya que la morfología de las palabras es suficiente para su interpretación.

La lengua germana es una lengua de CM, con orden SVo. A diferencia del latín, los sustantivos en alemán no suelen presentar mucha morfología de Caso. Este se proyecta a los demás elementos de la frase nominal en donde queda evidenciado. El paradigma de declinaciones del artículo definido en alemán se muestra a continuación: 
(21) Paradigma de declinaciones en alemán

\begin{tabular}{|c|c|c|c|c|c|}
\hline & Nom. & Acus. & Dat. & Gen. \\
\hline Masculino & der & den & dem & des \\
\hline Singular & Neutro & das & das & dem & des \\
\hline Femenino & die & die & der & der \\
\hline Plural & die & die & den & der \\
\hline
\end{tabular}

(22) Der Mann hat den Hut gekauft el.NOM hombre el.AC sombrero comprar.PERF 'El hombre compró el sombrero'

En (22) vemos una oración donde se muestran los dos argumentos del verbo comprar, cada uno con un Caso y una función diferentes. Ambos argumentos son sustantivos masculinos y están en singular. Sin embargo, Der Mann (el hombre) muestra Caso NOM y Den Hut (el sombrero) muestra Caso AC. Sabemos esto debido a que en esta lengua, como en muchas otras, los sustantivos (que no muestran cambio de forma) proyectan los cambios en sus determinantes. El argumento con Caso NOM tiene el determinante der mientras que el argumento con Caso $A C$-a pesar de ser también masculino singular- presenta el determinante en la forma den.

\section{SINCRETISMO}

El Caso de los argumentos está relacionado con las funciones gramaticales que estos realizan, como se mencionó líneas arriba. Así, el Caso NOM cumple la función de S (como en der Mann) y el Caso AC cumple la de 0 (den Hut). No obstante, 
suelen presentarse oraciones en las que tal diferencia no sea evidente. Oraciones en las que las formas de NOM y ACC, por ejemplo, sean iguales.

(23) Die Frau hat die Jacke
La.NOM mujer gekauft
'La mujer compró la.AC chamarra

En (23) encontramos que las formas de NOM y ACC no presentan diferencia. La forma die que precede a los sustantivos se encuentra en Caso NOM (como en die Frau) o en AC (die Jacke). Ambos argumentos son femeninos y están en singular. A este fenómeno se le conoce como sincretismo. Es importante mencionar que el hecho de que las formas de dos o más Casos no sean distintas no significa que los argumentos no tengan Caso ni que este se anule. Los argumentos, aún con la presencia de las formas sincréticas, tienen Caso y cumplen una función sintáctica dentro de la oración. Es decir, un argumento es $\mathrm{S}$ y el otro, 0.

El sincretismo se identifica tradicionalmente cuando una forma flexionada corresponde a dos o más funciones de Caso ${ }^{4}$ (Baerman 2013). La idea originalmente fue expuesta por Jakobson (1936) relativa al fenómeno que denomina sincretismo en su análisis de la morfología del verbo ruso, el autor define el sincretismo como la neutralización de la oposición de Caso en ciertas formas morfológicas. El fenómeno es bastante conocido y ha sido ampliamente analizado. Podemos encontrar un sinnúmero de

${ }^{4}$ We identify case syncretism when a single inflected form corresponds to two or more case functions. The criterion used here for identifying case functions is form-based:... 
textos que abordan el tema, siempre (o al menos en la mayoría de los casos) tomando como objeto de estudio lenguas de Caso (morfológico).

Debemos recordar que, siguiendo a Pesetsky y Torrego (2001), el Lenguaje está gobernado por reglas abstractas y, por lo tanto, son estas las que tenemos en mente y no únicamente las cosas más visibles.

Los fenómenos que aborda ese texto se encuentran dentro del marco de la lengua española. Como mencioné líneas arriba, en español el Caso se expresa mediante la concordancia (de persona y número) entre el $\mathrm{S}$ (NOM) y el verbo, que no se presenta entre el verbo y su objeto. El Objeto Directo (OD $[A C]$ ) no requiere marca normalmente.

El Caso DAT, tradicionalmente asociado al OI en lenguas como el español, presenta siempre la marca a que introduce al argumento que cumple esa función y se presenta como parte de la estructura argumental de algunos verbos ditransitivos del tipo dar.

(18) Juan escribió las cartas

(24) Juan dio los libros a María.

En (24) los argumentos con Caso NOM y AC tienen las mismas características que en (18) y el argumento con Caso DAT (María) se introduce por la marca a (siempre por la misma) y cumple la 
función de OI. El resto de los Casos en español se expresan siempre mediante el uso de preposiciones, de Caso genitivo (GEN), comitativo (COM), etc.

\section{PRINCIPIO DE CONTIGÜIDAD}

Como ya ha quedado claro, el sincretismo no es para nada inusual, sin embargo, tampoco es un fenómeno que aparezca de manera azarosa, sino sistemática. El fenómeno se presenta en las lenguas comúnmente pero está restringido por un Principio de Contigüidad (PC) presentado por Caha (2009) como parte de su Hipótesis de Sincretismo Adyacente (HSA). Dentro de HSA, el PC establece que el sincretismo de Caso en las lenguas obedece a un solo templete restrictivo. Un templete de Casos ordenados en secuencia en el cual únicamente las formas de Casos adyacentes muestran sincretismo.

El templete que presenta se muestra en (25)

$$
\begin{aligned}
& \text { (25) Nominativo - Acusativo - Genitivo - Dativo - } \\
& \text { Instrumenta - Comitativo }
\end{aligned}
$$

Tomando en cuenta el PC, el sincretismo que se muestra a continuación no presenta ningún problema:

(26) Griego moderno

a. o maxiti-s NOM

el.NOM luchador-NOM

'el luchador, NOM' 

b. $t$-on maxiti- $\varnothing A C$
el-AC luchador-AC
'el luchador, $A C$ '
c. $t$-u maxiti- $\varnothing$ GEN
el-GEN luchador-GEN
'el luchador, GEN'

En el ejemplo anterior podemos observar como el sustantivo maxiti- $\varnothing$ "luchador" presenta dos diferentes Casos, AC en (26b) y genitivo (GEN) en (26c). Este sincretismo es parte de lo esperado de acuerdo con el PC, ya que los Casos ACC y GEN se encuentran adyacentes en el templete.

Las posibilidades de sincretismo de Caso en las lenguas se muestran a continuación

(27) Formas sincréticas posibles

\begin{tabular}{lllll}
\hline \hline & NOM & ACC & GEN & DAT \\
\hline possible & & & & \\
possible & & & & \\
possible & & & & \\
possible & & & & \\
possible & & & & \\
possible & & & & \\
\hline$*$ & & & & \\
$*$ & & & & \\
$*$ & & & & \\
$*$ & & & & \\
$*$ & & & & \\
& & & & \\
\end{tabular}

Podemos ver entonces cuáles son los posibles sincretismos que se pueden presentar en las lenguas, que se encuentran previstos por el PC, y cuáles no se dan (pues no están permitidos). Sincretismos del tipo NOM-AC, AC-GEN, GEN-DAT, 
etcétera, son completamente esperados. Veamos otro ejemplo ahora con frases nominales como argumentos de un verbo en una oración.

(28) Sincretismo NOM-AC en alemán

a. Die Frau schwimmt.

La.NOM mujer nada.

'La mujer nada.'

b. Er küsst die Frau.

Él.NOM besa la.AC mujer

'Él besa a la mujer.'

En (28) vemos como el argumento die Frau presenta la misma forma a pesar de cumplir dos funciones diferentes en las oraciones. En la primera es el $\mathrm{S}$ del verbo nadar mientras que en la segunda, el OD de besar. Siguiendo la propuesta de Caha, esto es también parte del sincretismo esperado. El sincretismo de Casos NOM y AC es perfectamente válido ya que estos casos son adyacentes en el templete.

En su trabajo, Caha expone algunos lineamientos básicos que deben cumplirse para poder considerar dos (o más) formas sincréticas. En ellos explica por qué algunos aparentes sincretismos no lo son y ahonda en el uso de preposiciones funcionales, para las cuales se aplica el mismo templete con la misma restricción: solo Casos adyacentes pueden presentar 
sincretismo. El cuadro donde se resumen estos puntos se muestra a continuación:

(29) Lineamientos básicos

Universal (Case) Contiguity:

a. Non-accidental case syncretism targets contiguous regions in a sequence invariant across languages.

b. The Case sequence: NOM - ACC - GEN - DAT - INS - COM

The inventory of case suffixes:

a. If a given case in the Case sequence is a suffix, all cases to its left (if present in the language) are also suffixed.

b. The Case sequence: NOM - ACC - GEN - DAT - INS - COM

Universal Contiguity (Functional prepositions):

a. Only adjacent prepositional markers show systematic syncretism in the Case sequence.

b. The Case sequence: NOM - ACC - GEN - DAT - INS - COM

Universal Containment:

a. In the Case sequence, the marking of cases on the right can morphologically contain cases on the left, but not the other way round.

b. The Case sequence: NOM - ACC - GEN - DAT - INS - COM

Peeling and the Case sequence:

a. In the Case sequence, case on the right can change to any case on its left under movement, but not the other way round.

b. The Case sequence: NOM - ACC - GEN - DAT - INS - COM

\section{PROBLEMAS AL PC}

Los datos que se presentan en HSA son de muchas y variadas lenguas (en su mayoría lenguas de CM), lo cual soporta la idea de la universalidad del PC propuesto por Caha. No obstante, Rúnar (30), en su texto en respuesta al planteamiento de Caha, presenta un análisis de tres lenguas que no se consideraron en el corpus de HSA. Las lenguas que trabaja Rúnar son el nórdico antiguo, el islandés y el faroés. 
(30) Lenguas presentadas por Rúnar

Old Norse Iversen (1974)

\begin{tabular}{|c|c|c|c|c|}
\hline & a-stem M & a-stem N & o-stem F & an-stem $\mathrm{M}$ \\
\hline NOM & arm-r & land- $\varnothing$ & fjọðr- $\varnothing$ & grann-i \\
\hline ACC & arm- $\emptyset$ & land- $\varnothing$ & fjọðr- Ø & grann-a \\
\hline GEN & arm-s & land-s & fjọðr-a & grann-a \\
\hline \multirow[t]{2}{*}{ DAT } & arm-i & land-i & fjọðr- $\varnothing$ & grann-a \\
\hline & 'arm' & 'land' & 'feather' & 'neighbor' \\
\hline \multicolumn{5}{|c|}{ Modern Icelandic } \\
\hline & a-stem M & a-stem $\mathrm{N}$ & o-stem F & on-stem F \\
\hline NOM & arm-ur & land- $\varnothing$ & drottning- $\varnothing$ & tung-a \\
\hline ACC & arm- $\varnothing$ & land- $\varnothing$ & drottning-u & tung-u \\
\hline GEN & arm-s & land-s & drottning-ar & tung-u \\
\hline DAT & arm-i & land-i & drottning-u & tung-u \\
\hline & 'arm' & 'land' & 'queen' & 'tongue' \\
\hline
\end{tabular}

Faroese Práinsson et al. (2004)

\begin{tabular}{lllll}
\hline & Mclass 1 & N class 1a & F class 1a & F class 5 \\
\hline NOM & dag-ur & barn- $\emptyset$ & vørr- $\emptyset$ & tung-a \\
\hline ACC & dag- $\emptyset$ & barn- $\emptyset$ & vørr- $\emptyset$ & tung-u \\
\hline GEN & (dag-s) & (barn-s) & (varr-ar) & (tung-u) \\
\hline DAT & deg-i & barn-i & vørr- $\varnothing$ & tung-u \\
\hline & 'day' & 'child' & 'lip' & tongue' \\
\hline
\end{tabular}

En estas lenguas (de CM) existe sincretismo entre las formas de AC y DAT con la exclusión de GEN. Este sincretismo viola el principio expuesto por Caha ya que, como se presentó con anterioridad, estos Casos no se encuentran adyacentes en el templete.

Rúnar presenta su análisis y aclara el estatus de algunas formas sincréticas ( $A C-G E N$, sin DAT) que, según él y siguiendo el criterio de Caha, deben considerarse accidentales. Asimismo, su análisis abarca el remplazo del Caso GEN en faroés por una construcción prepositiva.

La conclusiones a las que llega Rúnar y su propuesta requieren del uso de llamado Caso Débil (o ligero) que permitiría un reordenamiento en el templete de casos y daría 
cuenta del nuevo estatus de GEN, no como forma sino como estructura con preposición. El templete que propone para lenguas nórdicas del oeste es el siguiente:

(31) nominativo - acusativo - dativo - genitivo

Esta versión arreglada del templete da cuenta del sincretismo sistemático de las lenguas que presenta Rúnar así como de sincretismo similares que puedan presentarse, como en español.

VIOLACIÓN AL PC EN ESPAÑOL

El objeto de estudio del presente trabajo es el sincretismo en la lengua española, no previsto por la teoría, que viola la restricción expuesta por Caha: El sincretismo que se presenta, sistemáticamente, entre los casos AC y DAT. Estos Casos se manifiestan de la siguiente manera en español.

(32) a. Juan vio unos libros.

b. Juan vio a unos amigos.

En (32) se presentan dos oraciones estructuralmente idénticas. Ambas con el verbo ver y sus dos argumentos requeridos. En las dos Juan cumple la función de $S$ pero el OD no presenta marca alguna en (32a) mientras que en (32b) requiere la marca $a$.

(33) a. Juan vio una casa. 


\section{b. Juan vio a María \\ c. *Juan vio María.}

En español, lengua que muestra el Caso por medio de la marcación en el núcleo de la oración (es decir, que presenta concordancia entre $\mathrm{S}$ y $\mathrm{V}$ pero no entre $\mathrm{V}$ y $\mathrm{OD}$ ), el argumento con Caso AC (el OD) no requiere ninguna marca cuando se encuentra bajo en la escala de animacidad y definitud. Lo cual representa el prototipo de la oración transitiva: S animado específico y OD inanimado no específico.

Sin embargo, cuando el $\mathrm{OD}$ es alto en dicha escala, principalmente por tener el rasgo [+ humano], se marca con $a$. A este fenómeno se le conoce como Marcación Diferencial de Caso $(M D C)$, es decir, que la lengua española presenta dos sistemas de marcación para el mismo argumento.

El tercer argumento de los verbos ditransitivos, el llamado beneficiario, siempre se marca con $a$, tal vez porque es generalmente humano. prototípicamente, una oración con tres argumentos tiene un argumento que concuerda con el verbo (S), uno no marcado, (OD) y uno marcado con $a$ (OI), que se relacionan con los Casos NOM, ACC y DAT, respectivamente.

El OD, entonces, presenta la posibilidad sistemática (bajo las circunstancias mencionadas líneas arriba) de estar marcado 
de la misma manera que el OI. Lo anterior se muestra a continuación.

(34) a. Juan vio a María.

b. Juan dio unos libros a María.

Los ejemplos de (34) muestran el sincretismo entre AC y DAT. La misma marca (a) se utiliza tanto para introducir al OD como al OI. Esto no sería una violación si la misma marca se utilizara para el Caso GEN. Pero esto resulta agramatical en la lengua.

$$
\begin{aligned}
& \text { (35) a. *El libro es a Juan. } \\
& \text { b. el libro es de Juan. }
\end{aligned}
$$

En este trabajo toma como punto de partida el sincretismo en la marcación de argumentos AC (con MDC) y DAT con la exclusión de GEN. El mismo tipo de sincretismo que encuentra Rúnar y que se relaciona con dos fenómenos más de la lengua que tienen como eje central los mismos elementos: las estructuras de OD y de OI.

En el siguiente capítulo profundizaré en el uso de las formas pronominales de AC y DAT, sus diferencias dialectales y el comportamiento, aparentemente, inesperado que presentan. 


\begin{abstract}
Novelty in the organism's physiology, anatomy, or behavior arises mostly by the use of conserved processes in new combinations at different times and amounts, rather than by the invention of completely new processes.
\end{abstract}

- Jacob

\title{
3. LEÍSMO
}

Dentro del estudio del español y sus características, un fenómeno ha llamado poderosamente la atención desde hace más de un siglo: el leísmo. Este tema (así como el fenómeno del loísmo y laísmo) se ha abordado desde diferentes perspectivas y, como es esperable, con diferentes resultados y explicaciones, pero siempre de manera aislada de otros fenómenos de la lengua.

La Real Academia Española define el leísmo como "el uso impropio de $L e(s)$ en función de complemento directo, en lugar de Lo (para el masculino singular o neutro), Los (para el masculino plural) y $L a(s)$ (para el femenino), que son las formas a las que corresponde etimológicamente ejercer esa función.”

(36) a. Vi a tu hermano; pero no lo/le reconocí.

b. Los romanos solían cocinarlo/le (el cerdo) entero.

c. Recogí a los niños y Los/les llevé al cine.

d. A la vecina hace tiempo que no La/le veo. 
En los ejemplos de (36) se observa la alternancia que presentan los pronombres de AC y DAT en español, el leísmo. Todos ellos son construcciones con verbos transitivos que requieren de acuerdo a la gramática prescriptiva únicamente un objeto directo (lo, los, la, las) y no uno indirecto (le, les).

Resulta importante mencionar que en los estudios del fenómeno, el término Leísta se utiliza con dos significados, que parecen si no contradictorios, sí opuestos. Por un lado, se suele llamar leísta al dialecto que utiliza le(s) para la función de OI frente a aquellos que utilizan lo(s)/la(s) (loístas, laístas). Y por otro lado, el término se usa exclusivamente para referirse al uso de le en función de OD. Es este último el significado al que me refiero en este texto.

\section{LEÍSMO COMO SINCRETISMO}

El uso de los pronombres de OI (DAT) en función de OD (AC) es un ejemplo del sincretismo que se presenta sistemáticamente en la lengua con respecto a las marcas o formas de Caso. El sincretismo que se encuentra en construcciones con frases nominales es el mismo que encontramos en el uso de los únicos elementos que conservan morfológicamente las marcas de Caso heredadas del latín. 
El uso de le con funciones de OD así como de OI lo ubican dentro del marco de la violación al PC, presentado en el capítulo anterior.

(37) a. Vi a tu hermano; pero no Le reconocí.

b. *El libro es Le.

c. Le compré un regalo (a Juan).

En (37) vemos los usos aceptados de Le como (a) OD y (c) como OI. Sin embargo, consistentemente con los ejemplos presentados en el capítulo anterior, la forma le no se puede utilizar para el Caso GEN. Es decir, se presenta un sincretismo de formas no adyacentes en el templete de Casos, lo cual resulta en una violación al PC propuesto por Caha.

(38) SISTEMA PRONOMINAL DEL ESPAÑOL

$\begin{array}{lll}\text { AC } & \text { GEN }\end{array}$

1 SG Me de mí me

2 SG Te de ti te

3 SG

masc. lo / le de él le

3 SG

fem. La / le de ella le

$1 \mathrm{PL}$ Nos de nosotros nos

$3 \mathrm{PL} \operatorname{los}(\mathrm{as}) / \mathrm{le}$ de ellos(as) les 


\section{TIPOS DE LEÍSMO}

El leísmo presenta una distribución muy distinguible con respecto a los rasgos del argumento que se sustituye por $\operatorname{Le}(s)$. Se pueden distinguir distintos tipos de leísmo: el de OD masculino, dentro del cual el uso más frecuente, e incluso el más recomendado por la RAE hasta la cuarta edición de su gramática en 1796, es el de persona, y con menos difusión el de cosa. El de OD plural, menos frecuente que el de singular. Y por último, con un uso sumamente restringido y no pocas veces condenado, el de OD femenino.

PROPUESTAS DE ANÁLISIS

Debido a la naturaleza misma del fenómeno, a su distribución geográfica y a diferentes aspectos sociolingüísticos, el estudio del leísmo ha partido desde diferentes supuestos teóricos y se ha analizado con diferentes metodologías. A continuación presento un breve recuento de las propuestas más representativas.

La primera manera de analizar el fenómeno data de finales del siglo XIX. Cuervo es el principal representante de las llamadas "hipótesis tradicionales" que ven el uso innovador de los clíticos de OI (y los de OD) como una extensión analógica del sincretismo de los pronombres de primera y segunda personas. 
Estas hipótesis promueven la idea de que el leísmo se explica a partir de la eliminación del Caso a favor del género.

De esta manera podría explicarse no solo el fenómeno leísta sino también el loísmo y el laísmo (uso de formas de AC con función de DAT). El leísmo, desde este punto de vista habría afectado únicamente al OD masculino ya que, como resalta Fernández Ramírez, existía un deseo de mantener la distinción genérica entre masculino y neutro, misma que se perdía con el uso de Lo para AC singular masculino y neutro.

El uso no apegado a la regla etimológica era entonces el inicio de la constitución de un sistema unicasual que respondía a las diferencias de género y no a las de Caso. Este sistema estaría basado en el paradigma de los demostrativos (este, esta, esto) y se utilizaría de la siguiente manera: le como forma para masculino; la, para femenino y; lo, para neutro. Todas estas formas sin importar el Caso del argumento, AC o DAT.

Resulta particularmente interesante pensar en las motivaciones que explicarían el leísmo desde el ángulo de las hipótesis tradicionales. Se propone el abandono de las funciones "etimológicas" a favor de la distinción de género, cuyo valor tripartita, al menos en los sustantivos, también sería etimológico. Es decir, en la lengua española se distinguen únicamente dos géneros: masculino y femenino. 
(39) Sistema pronominal unicasual

OD / OI

$1 \mathrm{SG}$

Me

$2 S G$

Te

$3 S G$

Masc.

Le

3 SG

Neutro

Lo

3 SG

Fem.

La

$1 \mathrm{Pl}$

Nos

$3 \mathrm{PL}$

Masc. /

Los

Neutro

$3 \mathrm{PL}$

Fem. Las

El nuevo paradigma de formas pronominales habría tomado como modelo el de los demostrativos que distinguen entre los tres géneros heredados del latín (masculino, femenino y neutro). A pesar de que tal diferencia no se mantiene en plural, donde parece no importar la diferencia entre masculino y neutro.

También debemos recordar la tendencia latente del español, como en tantas otras lenguas indoeuropeas, a distinguir entre 
entes animados e inanimados, la misma tendencia que parece explicar el uso de $a$ ante OD personales, que se podría considerar otro factor que habría originado el leísmo. Asimismo, el uso de algunos verbos (transitivos en español) que regían dativo en latín habría ayudado a la extensión del uso de le en contextos de complementos (OD) personales. Verbos del tipo ayudar, obedecer.

Al revisar los ejemplos de (36) resultan claras las limitaciones explicativas de las hipótesis tradicionales. Es decir, (36c y d) muestran ejemplos de leísmo que no se encuentran dentro del marco propuesto. Los ejemplos en los cuales se hace uso de Le para referirse a OD plural o femenino no quedan explicados con estas propuestas de análisis.

(36) a. Vi a tu hermano; pero no Lo/Le reconocí.

b. Los romanos solían cocinarlo/le (el cerdo) entero.

c. Recogí a los niños y Los/Les llevé al cine.

d. A la vecina hace tiempo que no La/le veo.

Debido a las limitaciones de las hipótesis tradicionales surgen las "nuevas hipótesis". Propuestas que ponen énfasis en factores semánticos y pragmáticos. Es un giro importantísimo al acercamiento al fenómeno no solo por las explicaciones a las que se llegan sino por el cambio metodológico que conllevan y el uso de datos de lengua hablada. 
En 1975, García presenta su primer trabajo acerca del fenómeno y con él una nueva manera de interpretar los datos que obtuvo del español escrito y hablado del dialecto argentino. Según su propuesta se debe partir de las construcciones en las cuales la variación no es posible para así poder comprender las diferencias semánticas que los hablantes desean transmitir a través de la variación sintáctica.

De acuerdo con esta propuesta, la “hipótesis comunicativa”, el uso de clíticos de diferente Caso responde a los grados de participación del argumento en el evento. Así, habría una escala de actividad y participación, con el Caso NOM como el más activo y más participativo en un extremo; el DAT con un nivel de actividad y participación medio y; el Caso $A C$ en el extremo opuesto (como el argumento menos activo y menos participativo).

El empleo, en construcciones de $\mathrm{OD}$, de Lo tendría semánticamente un argumento paciente nada activo y poco participativo de la acción verbal. En cambio, cuando el OD es animado y activo su participación en el evento es mayor y, entonces se prefiere el empleo de la forma le.

Con este y otros trabajos, la autora se acerca a la explicación de la elección del clítico de AC o DAT, dependiendo de los rasgos semánticos y la intención comunicativa diferenciada del hablante. 
Flores, en su propuesta, simpatiza con la hipótesis comunicativa pero menciona que aunque el grado de actividad de los participantes en el evento es importante, no es suficiente para la correcta explicación de la alternancia de las formas pronominales. Agrega que es necesario, entre otros factores, resaltar el nivel de afectación de los argumentos participantes.

Desde esta perspectiva se asume la postura de que la transitividad del evento en la lengua española debe ser tratada como un elemento más amplio. Un elemento que incluye, entre otros factores, la agentividad del sujeto, algunas características propias del evento (telicidad, perfectividad, puntualidad) y la individuación del objeto. La transitividad del evento, el grado de afectación del objeto y la participación de este en el evento serían los rasgos que darían cuenta de la variación.

La jerarquía mencionada anteriormente se vería enriquecida con un elemento más: el nivel de afectación del objeto. De esta manera, en un extremo se ubicaría el sujeto (NOM), como el argumento más activo, más participativo y menos afectado; el DAT, en un nivel intermedio (menor que el NOM) en actividad y participación pero que sí resulta afectado de alguna manera por la acción verbal y; en el extremo opuesto el AC, argumento que se encuentra prácticamente inactivo, menos participativo en el evento y más afectado que cualquier otro. 
Como podemos apreciar, el fenómeno del leísmo es un asunto que no ha terminado de explicarse y que presenta muchos puntos de análisis interesantes. Dentro del marco de este trabajo, que no se enfoca en el leísmo en particular sino en un conjunto de fenómenos que involucran el uso sincrético de formas de Caso no adyacentes, se presentará en el capítulo siguiente una propuesta de análisis que da cuenta del estatus de las construcciones ditransitivas (del tipo ATR), brinda nuevos elementos al estudio del leísmo y sugiere un análisis profundo de los rasgos relacionados y activados por medio del uso de a (ante objetos). 


"Sería insensato, y contradictorio en sí
mismo, pensar que es posible hacer lo que
hasta ahora nunca se ha hecho por
procedimientos que no sean totalmente
nuevos."
Novum Organum, I, 6.

\section{CONSTRUCCIONES DE DOBLE OBJETO}

\section{TRANSITIVIDAD}

El estudio de la transitividad se encuentra, como ya advertían Hopper y Thompson desde hace varias décadas (1980), en el núcleo de la explicación de la mayoría de los procesos gramaticales. La transitividad, para efectos de la tipología se debe entender como la codificación de eventos básicos. Como es común en los estudios tipológicos, la base semántica es de vital importancia, pues es por este medio que se puede realizar una comparación de estructuras entre la variedad de posibilidades que existen en las lenguas.

Como punto de partida debemos considerar la definición semántica de la transitividad prototípica, que incluye dos conceptos básicos: agente $(A)$ y paciente $(P)$. El agente, como lo define Kittilä (2010), es el responsable del evento, su causa visible; mientras que el paciente es el que registra el cambio de estado del evento, su efecto visible. 
El evento prototípicamente transitivo incluye, por un lado, un A con voluntad, control y que activamente inicia el evento, $y$, por otro lado, un $\mathrm{P}$ sin voluntad, sin control e inactivo. Estas definiciones consideran el evento transitivo prototípico por sus cualidades semánticas y toman como base el grado de afectación del $\mathrm{P}$, así como el nivel de agentividad del A. La construcción transitiva más natural es aquella en la que el A y el $P$ se encuentran lo más clara y mayormente diferenciados semánticamente.

Para que una estructura se considere formalmente transitiva debe presentar sus dos argumentos de manera observable. Sin embargo, las construcciones transitivas pueden sufrir diferentes procesos en los que el número de argumentos requeridos por el verbo cambie. A estos procesos se les conoce como cambio de valencia y existen principalmente de dos tipos.

a) De disminución de valencia. Son procesos que reducen el número de argumentos explícitos en una construcción particular. Entre las alteraciones de este tipo más comunes se encuentran la pasiva, antipasiva, anticausativa y reflexiva.

Estos procesos no solo disminuyen el número de argumentos en una construcción originalmente transitiva sino que también cambian la función gramatical de los elementos que permanecen. 
Esto se puede caracterizar en los siguientes términos (Perlmutter and Postal 1977):

- Pasiva: sujeto $\rightarrow$ oblicuo (o nulo); objeto $\rightarrow$ sujeto.

- Antipasiva: objeto $\rightarrow$ oblicuo (o nulo).

- Aplicativa: oblicuo/objeto indirecto $\rightarrow$ objeto; objeto $\rightarrow$ objeto secundario (u oblicuo).

b) De aumento de valencia (transitivizadoras). Son procesos que aumentan el número de participantes en una construcción, la causativa y aplicativa son las alteraciones más típicas en las lenguas.

\section{CONSTRUCCIONES DITRANSITIVAS}

Existen también construcciones que presentan dos participantes aparte del sujeto. Las primeras del tipo Puse el Libro en la mochila, las cuales se encuentran fuera del interés en este texto, ya que uno de los argumentos se encuentra claramente introducido por una preposición. Y las que consisten en un verbo ditransitivo, un agente, un argumento (tipo-) receptor ( $R$ ) y un argumento Tema ( $T)$. Las segundas, que son las que consideraremos en este trabajo, son las construcciones que se conocen como construcciones ditransitivas. La definición se basa en el significado de la construcción (mientras que la manera en que se manifiestas estos participantes es 
irrelevante, por el momento,) para poder establecer los parámetros de comparación tipológica.

De la misma manera que hablamos al principio del texto de la construcción prototípicamente transitiva, lo haremos ahora de la típica construcción ditransitiva. Esta es, siguiendo a Haspelmath (2010), la que contiene un verbo de transferencia física -como dar o vender- que describe la escena en la cual un A causa que un $T$ pase a la posesión de un $R$ animado.

Otra construcción muy parecida a la construcción ditransitiva es la de beneficiario (que en muchas lenguas se codifica de la misma manera pero) que difiere de la primera ya que puede ocurrir también con verbos intransitivos (Ella canta para mí). Asimismo, los mecanismos de aumento de valencia mencionados anteriormente, casusativas y aplicativas, pueden dar paso a construcciones ditransitivas que (comúnmente) se consideran derivadas.

Probablemente el verbo dar sea el verbo ditransitivo más frecuente (y el más observado) y por tal motivo se considera el verbo ditransitivo prototípico de las construcciones ATR. Analizaremos a continuación la variación en la codificación de este tipo de construcciones.

Con el fin de poder analizar construcciones monotransitivas y ditransitivas bajo los mismos parámetros, se hace uso de lo 
que llamamos alineamiento. El alineamiento se refiere a la comparación de las propiedades de los argumentos entre construcciones $^{5}$. El parámetro de variación que se examina es la relación entre las propiedades de codificación de los dos objetos ditransitivos y las del único objeto en una construcción monotransitiva. Es decir, la manera de codificar $T$ y $R$ con respecto a $\mathrm{P}$.

Existen tres tipos principales de construcciones ditransitivas:

a) La construcción de objeto Indirecto (OI), o alineamiento indirectivo, donde $R$ se codifica diferentemente de $P$ y $T$ $(\mathbf{T}=\mathbf{P} \neq \mathbf{R})$. Estas construcciones también suelen ser llamadas construcciones dativas.

b) La construcción de Objeto Secundario (OS), en la cual el T se trata de manera diferente de $P$ y $R(T \neq P=R)$. en estas construcciones el $\mathrm{P}$ y el $\mathrm{R}$ se agrupan como el objeto Primario (OP)

c) Alineamiento neutro. En esta construcción el P, el R y el $\mathbf{T}$ se codifican de la misma manera $(\mathbf{T}=\mathbf{P}=\mathbf{R})$. Estas construcciones también son llamadas construcciones de doble objeto (CDO).

\footnotetext{
${ }^{5}$ Originalmente el alineamiento se utiliza para comparar al único argumento de una construcción intransitiva (S) con los argumentos de la construcción monotransitiva (A) y (P). Lo cual arrojaba como resultado tres tipos diferentes: (nominativo-) acusativo $(\mathbf{S}=\mathbf{A} \neq \mathbf{P})$; ergativo (-absolutivo) $(S=P \neq A) ; y$ el neutro $(S=A=P)$.
} 
A continuación se presenta el esquema de representación de alineamiento.

(40) Mapa de alineamiento de construcciones ditransitivas

Indirectivo

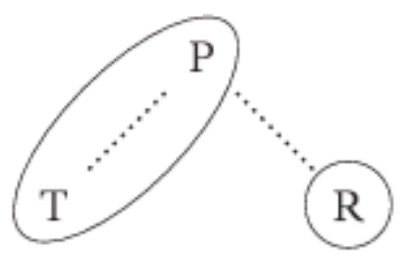

Secundativo

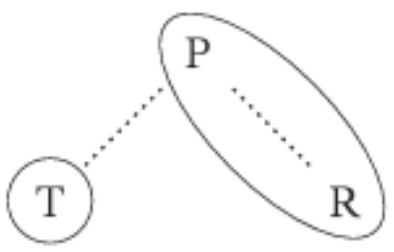

Neutro

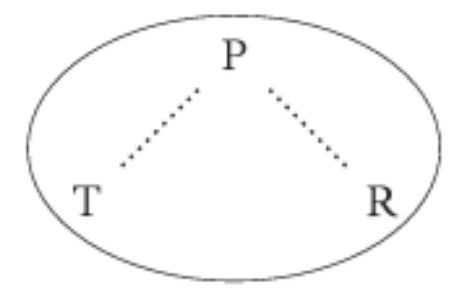

Estos alineamientos, empero, presentan algunas separaciones (splits), siendo las más conocidas las de construcciones monotransitivas. Algunos de los factores que mayormente influyen en estas separaciones son los niveles en las escalas de animacidad, definitud y persona.

MDO

Algunas lenguas muestran la Marcación Diferencial de Objeto, Differencial Object Marking (DOM), que es una marca de caso especial en el $\mathrm{P}$ de construcciones monotransitivas.

Este es un fenómeno común en las lenguas de caso explícito. La marcación de algunos objetos y otros no, dependiendo de su grado de animacidad o definitud, principalmente.

MDO se puede caracterizar de la siguiente manera: 
- Mientras más alto en prominencia sea el OD, más probable será que esté marcado explícitamente.

- Los OD que presenten mayor necesidad de ser distinguidos de los sujetos serán los que se marquen.

- Los OD que más se asemejen a los sujetos prototípicos (A) serán marcados.

Según Comrie 1989, el tipo de construcción transitiva más natural es aquel en el que $A$ es altamente animado y definido, y $P$ es bajo en animacidad y definitud; cualquier desviación de este patrón nos lleva a una construcción más marcada, ya que funcionalmente es más sencillo comprender objetos atípicos cuando se encuentran marcados.

En seguida se presentan las escalas de animacidad y definitud que principalmente influyen en la ocurrencia de MDO.

a) Escala de animacidad: Humano > Animado > Inanimado

b) Escala de definitud: Pronombre personal > nombre propio > FN definida > FN específica indefinida > FN no específica.

La aparición de MDO se puede caracterizar de la siguiente manera:

- Construcción transitiva:

A [humano/definido] y $P$ [inanimado/indefinido]

a) Juan vio un libro

MDO $\rightarrow \mathrm{P}$ [humano/definido] 
b) Juan vio a María.

Resulta importante hacer notar que, como retoman Hopper y Thompson de Comrie, un morfema de dativo frecuentemente se reanaliza como marcador de definitud o animacidad en objetos. Entonces, la marca a del español, a pesar de ser etimológicamente un marca de dativo, puede ser considerada como una marca de acusativo animado/definido. Lo cual abre la posibilidad de reanalizar las construcciones ditransitivas ATR del español como CDO, o al menos como construcciones de OS. En ese sentido podríamos postular la existencia de dos tipos de alineamiento en español: a) indirectivo; y b) CDO u OS.

ARGUMENTO DATIVO

El argumento DAT, que corresponde semánticamente con el elemento (tipo-) receptor en las construcciones ditransitivas y que se conoce como $\mathrm{OI}$, no es un elemento exclusivo de construcciones con verbos ditransitivos. No solo los verbos del tipo dar admiten su uso.

En español existen construcciones con verbos transitivos que admiten la inclusión de un argumento más, un argumento que suele presentar diferencias en la marcación. Este tercer argumento no es pate de la estructura semántica original del verbo pero se puede agregar y representa, normal aunque no exclusivamente, a un argumento tipo beneficiario. 
Este tipo de argumentos se pueden incorporar a la estructura del verbo por diferentes medios: por afijación verbal, con un núcleo aplicativo, o sin marca particular alguna, como es el caso de la construcción de doble objeto de la lengua inglesa.

\section{TIPOS DE DATIVO (APLICATIVO)}

Los argumentos dativos, como bien señala Cuervo (2003), son opcionales en muchos casos pero pueden aparecer con muchos tipos de verbos y presentar diferentes interpretaciones: recipiente, beneficiario, origen (fuente), posesor, afectado, experimentante o, el llamado dativo ético. Los ejemplos se muestran a continuación ${ }^{6}$.
a. Juan le puso azúcar al café.
b. Juan les preparó sándwiches a todos.
c. Juan le robó la bicicleta a María.
d. Juan le lavó el carro a María.
e. Juan le rompió el teléfono a María.
f. A Juan le gustan los gatos.
g. Su hijo ya le camina (a Juan).

Debido a que el argumento dativo no es un argumento exigido por el verbo, su aparición requiere una estructura particular: La estructura con el clítico dativo, que a diferencia del

\footnotetext{
${ }^{6}$ Los ejemplos son versiones en dialecto mexicano de los ejemplos de Cuervo rescritos por mí.
} 
clítico AC no solo permite la substitución de un argumento sino que admite que ambos aparezcan en la oración.

$$
\begin{aligned}
& \text { a. Juan compró un libro. } \\
& \text { b. Juan le } e_{i} \text { compro un libro a María }
\end{aligned}
$$

En (42) vemos dos oraciones con el mismo verbo. En ambas Juan cumple la función de $\mathrm{S}$ y un Libro, la de OD. En (42b) el argumento María, que se presenta coindexado con Le, cumple la función de OI. El verbo, como mencioné líneas arriba, no exige ese tercer argumento. Sin embargo, este se puede incorporar a la estructura semántica del verbo mediante un núcleo aplicativo.

El elemento incorporado a la estructura verbal que hemos venido llamando argumento dativo recibe este nombre por razones claramente semánticas. No obstante, esto no significa que el argumento se encuentre en Caso DAT. Usamos el concepto para poder dar cuanta de construcciones que incluyen a los argumentos ATR .

CASO PROFUNDO

La oración consiste básicamente en un verbo y una o más frases nominales, que se relacionan con el verbo mediante un Caso particular. Como menciona Fillmore (1968), "es importante darse cuenta de que el valor explicativo de un sistema universal de casos de la estructura profunda es de naturaleza sintáctica y no (meramente) morfológica.” 
La manera en que se presentan los argumentos de un verbo en las construciones ( $y$ los Casos en que estos aparecen) no representa necesariamente la manera en que entendemos las oraciones. Es decir, el sujeto de una oración, por ejemplo, no es necesariamente quien realiza la acción verbal. Se muestran algunos ejemplos de Fillmore a continuación ${ }^{7}$.
a. Juan rompió la ventana.
b. Un martillo rompió la ventana.
c. Juan rompió la ventana con un martillo.

En (43) vemos la relación que establece un agente y un instrumento con el verbo romper. Mientras que en (43a y c) el agente es el sujeto de la oración (NOM), en (3b) el sujeto gramatical es el instrumento. En (43c), en donde aparecen ambos elementos, el instrumento aparece introducido por una preposición, es decir, en Caso Oblicuo.

En su texto Filmore presenta las nociones de caso que incluyen un set de conceptos universales que los humanos somos capaces de crear acerca de los eventos que suceden a nuestro alrededor. El cuadro con los Casos (Profundos) y sus definiciones se presenta a continuación.

(44) Nociones de Caso Profundo.

- Agentivo (A), el caso del típico instigador animado de la acción que se identifica por el verbo.

\footnotetext{
${ }^{7}$ La traducción de los ejemplos es mía.
} 
- Instrumental (I), el caso de la fuerza inanimada u objeto que de manera casual se relaciona con la acción o estado identificado por el verbo.

- Dativo (D), el caso del ser animado que resulta afectado por el estado o la acción identificada por el verbo.

- Factitivo (F), el caso del objeto o del ser resultado de la acción o estado identificado por el verbo, o entendido como parte del significado del verbo.

- Locativo (L), el caso que identifica la locación o la orientación espacial del estado o acción identificado por el verbo.

- Objetivo (O), el caso semánticamente más neutral, el caso de cualquier cosa representable por un sustantivo cuyo rol en la acción o estado identificado por el verbo se identifica mediante la interpretación semántica del verbo mismo; se concibe que el concepto debería estar limitado a cosas que son afectadas por la acción o estado identificado por el verbo. El término no debe confundirse con la noción de objeto directo (OD), ni con el nombre del caso superficial sinónimo de acusativo.

La estructura semántica del verbo dar, que conocemos como construcciones ATR, bajo este pensamiento incluye un 0 , un D y un A. Recordemos que estas nociones de caso no se alinean necesariamente con los casos que se observan a simple vista, y resulta importante enfatizar que todos los elementos deben presentar casos diferentes y que ningún caso puede repetirse dentro de una oración.

CONSTRUCCIONES DE DOBLE OBJETO

Sigo la tesis expuesta por Cuervo quien considera que las oraciones ditransitivas en español se dividen en dos tipos: las que introducen al argumento dativo mediante la preposición a y las que lo incorporan con el uso del núcleo aplicativo Le.

Según su análisis y propuesta, las construcciones que no duplican el argumento dativo con la frase nominal y el clítico 
son construcciones prepositivas. Así, tenemos construcciones ATR que presentan un argumento con Caso AC y otro con Caso Oblicuo (OBL), como en (45).

(45) Juan dio flores a María.

(46) Juan $\mathrm{le}_{i}$ dio flores a María .

Mientras que (46), que incluye la duplicación del argumento dativo, la estructura ATR es de tipo Construcción de Doble Objeto, comparable con la CDO de la lengua inglesa pero que difiere sustancialmente ya que esta presenta un núcleo aplicativo que introduce al argumento dativo y le asigna rol temático. 


\section{CONSECUENCIAS}

En su famoso texto "On the Double object Construction" (1988), Larson ofrece un análisis de las asimetrías de dominios presentadas por Barss y Lasnik (1986) con respecto a las construcciones de doble objeto. Los autores subrayan que una teoría que mantuviera la estructura tradicional de las CDO y que también basara los lineamientos de dominio únicamente en el C-comando asimétrico no podría dar cuenta de tales asimetrías.

Larson, en cambio, presenta el análisis opuesto en el que asegura que las asimetrías se pueden explicar mediante el uso de C-comando asimétrico. Jackendoff (1990), por su parte, analiza los datos presentados por ambos y critica con severidad el análisis de Larson, para lo cual desglosa ampliamente las propuestas de ambos textos.

El interés del presente trabajo no está en las asimetrías mencionadas sino en las CDO en español que, según Larson, no están permitidas por cuestiones de marcación y asignación de papeles temáticos.

De acuerdo con el autor, las CDO en las diferentes lenguas son comparables con el dativo oblicuo de manera transformacional. Pues a pesar de las irregularidades que presentan las estructuras en inglés, en lenguas con 
construcciones aplicativas ( $A P L$ ) existe una relación sistemática.

Larson argumenta que las CDO en inglés están permitidas principalmente porque la preposición to asigna Caso objetivo, lo cual permite que las preposiciones sean reanalizadas temáticamente con el verbo cuando el objeto preposicional se extrae. En lenguas como el español o el francés la posibilidad queda bloqueada debido a que la preposición asigna Caso OBL.

Los datos que presenta el autor, que compara con las CDO en inglés, y con los que muestra la prohibición del español y del francés para crear dichas estructuras son los siguientes:

(47) Ejemplos de Larson

Español

a. i. Juan dio un libro a María.

ii. *Juan dio María un libro.

Francés

b. i. Jean a donné un livre à Marie

ii. *Jean a donné Marie un livre.

Sin duda (47aii y 47bii) resultan agramaticales en español y francés, lo cual parece sustentar la explicación de Larson. Sin embargo, el autor no considera lo que él mismo menciona en el mismo trabajo: "[...] in languages with so-called applicative constructions", el autor incluso cita a Marantz (1984) y a Baker 
(1985) para ampliar la discusión, "oblique and double object structures show a highly productive relation strongly suggestive of derivational relatedness".

La lengua española, a diferencia del francés, se encuentra dentro de lo que el autor llama lenguas con construcciones aplicativas, que, siguiendo el pensamiento de Marantz, permiten introducir nuevos elementos a la estructura verbal. Si bien el clítico le del español no es un afijo verbal, sí tiene las características necesarias de los afijos aplicativos. Es, sin duda, el núcleo de la construcción APL y no solo permite la construcción de estructuras con elementos incorporados como la CDO en inglés, sino que excede las posibilidades de esta. Como mencioné antes, las CDO en español admiten muchas otras interpretaciones además de la de beneficiario (goal) como son: recipiente, origen (fuente), posesor, afectado, experimentante y el dativo ético. Significados que resultan imposibles para la CDO en inglés.

Los problemas para la creación de CDO en lenguas romance, como el español o el francés, que menciona Larson, poco tienen que ver en dichas construcciones en la lengua española. Pues el elemento encargado de asignar caso (AC) y papel temático al elemento introducido no es el verbo sino el núcleo APL Le.

La mal llamada preposición de objeto indirecto $(a)$ es en realidad la marca de Caso AC que sigue los parámetros planteados 
en la MDC de los objetos de verbos monotransitivos, objetos que se alejan del prototipo básico de paciente y que, por lo tanto, se presentan mancados comúnmente.

En español, como mencioné anteriormente, existen dos estructuras para las construcciones ATR: las de alineamiento indirectivo, en las cuales $\mathrm{R}$ aparece introducido por la preposición a (o para); y las CDO, que presentan a ambos objetos, T y R, sin preposiciones. 


\section{CONCLUSIONES}

A lo largo del presente trabajo he abordado el tema del sincretismo de Caso en tres elementos de la lengua española: (aparentes) preposiciones para introducir objetos, frases nominales y pronombres en función de objeto. En ellos los Casos AC y DAT parecen encontrarse en conflicto, o al menos con límites difusos.

Los temas mencionados han sido estudiados de manera independiente (MDC: Bossong, Aissen; leísmo: Cuervo, Fernández Ramírez, García, Flores; CDO: Larson, Demonte, Cuervo). Sin embargo, en este trabajo se presentan unificados todos ellos desde el punto de vista del Caso.

En el marco de la nanosintaxis y como parte de la HSA, Caha propone el PC, que, según su análisis, da cuenta del sincretismo existente entre las formas de Caso en las diversas lenguas. El español no se presenta como parte de los datos pero, al pretender ser una hipótesis con alcances universales, los fenómenos deberían estar previstos por la teoría.

El PC, como describí en el capítulo 2, propone un templete restrictivo de posibles sincretismos de Caso. La lengua española presenta una (aparente) violación sistemática a dicho principio. Los límites entre las formas de AC y DAT parecen no estar bien definidos y suelen presentarse contextos en que ambas 
formas se utilicen (ya sea porque son semánticamente muy similares, porque el hablante desea diferenciar el nivel de participación o por razones de carácter sociolingüístico).

Tal tipo de sincretismo, entre formas no adyacentes, se encuentra presente en lenguas ajenas a las romance y de él se ha dado cuenta mediante el uso del llamado Caso débil (Rúnar). En este trabajo, en cambio, se dio mayor importancia al tipo de construcciones en que se presenta el sincretismo, y las características que presentan los argumentos involucrados.

Los elementos que presentan sincretismo son: la marcación de objeto directo (MDC) e indirecto (preposicional), el objeto directo (MDC) y el objeto indirecto, y la forma pronominal de tercera persona le.

La diversidad de significados en las construcciones ditransitivas (ATR) en español, nos llevaron a poner el énfasis en las CDO. En dichas estructuras el elemento $R$ presenta características particulares que la distinguen de las CDO en lenguas como el inglés.

La principal diferencia que se observa en las CDO en español es, sin duda, la estructura sintáctica. Estas construcciones, a diferencia de las CDO como en inglés, son de tipo APL, es decir, presentan un elemento que permite la incorporación del argumento (tipo-) receptor. El núcleo de la 
construcción APL, sin embargo, no es un sufijo verbal, sino un elemento que se comporta como clítico o pronombre.

La CDO en español, entonces, introduce a un elemento (tipo) receptor que se muestra con Caso AC y sigue los lineamientos de la MDC, pues se aleja del prototipo básico de paciente. Es en realidad un argumento dativo (en el sentido de los Casos profundos de Fillmore), el argumento (comúnmente) animado que resulta afectado por la acción identificada por el verbo.

La CDO presenta a los dos objetos con Caso AC, a diferencia de la construcción ditransitiva. En la construcción de OD-OI, el argumento $\mathrm{R}$ se introduce por la preposición a para el verbo dar (y los verbos que más se asemejan a la estructura de este, como comprar) y con para, en el caso de los verbos monotransitivos que presentan un elemento $\mathrm{R}$ con Caso $\mathrm{OBL}$, como adjunto.

(48) a. Juan dio libros a María

(49) a. Juan escribió un poema para María.

b. (?) Juan escribió un poema a María.

c. *Juan escribió un poema a ella.

Como podemos ver en (49c), al cambiar la frase nominal por el pronombre el resultado es una construcción agramatical. (49b) es una construcción que podría ser aceptable, pero esto es así solo por la fuerza (por analogía al Caso AC de las CDO) frente a frases nominales, que permite la interpretación de beneficiario. 
En la estructura ATR, la CDO incluye un núcleo APL, lo cual permite la incorporación de diferentes tipos de argumento, con diferentes significados. Desde el elemento receptor o beneficiario (incluso con elementos no-animados) como en (50a y 50b), hasta el de tipo fuente o poseedor (50c y 50d)

$$
\begin{aligned}
& \text { (50) Juan le trajo flores a María. } \\
& \text { b. Juan le arregló la pata a la mesa. } \\
& \text { c. Juan le quitó el dinero a María. } \\
& \text { d. Juan le arregló el carro a María. }
\end{aligned}
$$

Es el núcleo de la construcción APL el que asigna Caso a la frase nominal que introduce, así como papel temático que (a diferencia del inglés) puede tener otros valores y no solo beneficiario (goal). Es esta la segunda característica de estas construcciones.

Un punto hasta ahora no explorado (o al menos que no conozco) es la posible analogía, que podría explicar el uso del pronombre "dativo" en contextos donde se espera el de AC (leísmo), que se presentaría debido a la extremadamente alta productividad de la CDO en español.

Al presentar un abanico amplio de significados para el argumento incorporado, la CDO presenta construcciones APL perfectamente aceptables que se asemejan a las construcciones 
con el uso inesperado del pronombre Le. Los ejemplos se muestran en (51) y (52)

(51) a. María vio a Juan.

b. María Lo vio.

(52) a. María le vio la herida a Juan.

b. María Le vio (a Juan).

Es tan fuerte y productiva la construcción APL en español que incluso en las construcciones con el verbo ditransitivo canónico dar, que aceptan la presencia de ambos objetos sin el núcleo $A P L$, se prefiere el uso de la CDO.

a. Juan dio flores a María.

b. Juan le dio flores a María

Los datos estadísticos no son parte del objetivo de este trabajo, y por lo tanto no se encuentran aquí. Sin embargo, resulta interesante plantear la hipótesis de la frecuencia de uso de la CDO con el verbo dar (en lugar de la estructura indirectiva), así como de la analogía entre construcciones transitivas y $\mathrm{CDO}$ en tanto al uso del elemento Le.

La aparente violación al PC de Caha no es en realidad un caso de sincretismo, pues, si bien un argumento se muestra en caso objetivo y el otro en caso DAT, esto es únicamente en cuanto a la semántica de la construcción. En la estructura sintáctica, ambos argumentos se encuentran en Caso AC, lo cual 
significa que el aparente sincretismo por el cual surgió esta investigación no se encuentra presente en la lengua.

Con respecto al leísmo, es importante señalar que en el caso de los pronombres, que son elementos que siempre requieren una referencia, las diferencias y similitudes responden a lo que el hablante desea transmitir (por un lado) y a los medios sintácticos con los que cuenta para ello (por otro).

Resulta necesario profundizar en el estudio de las estructuras con frases nominales y sus contrapartes con elementos pronominales para poder dar cuenta de sus similitudes y, principalmente, de sus diferencias. 
Referencias bibliográficas:

- Aissen, Judith. 2003. Differential object marking: Iconicity vs economy. Natural Language and Linguistic Theory 21.3

- Baker, Mark. 1988. Incorporation: a Theory of grammatical Function Changing. Chicago: University of Chicago Press.

- Blake, Barry J. 2001. Case $2^{\text {nd }}$ ed. Cambridge: CUP

- Bossong, Georg. 1991. 'Differential Object Marking in Romance and Beyond', in D. Wanner and D. Kibbee (eds.), New Analyses in Romance Linguistics: Selected Papers from the XVIII Linguistic Symposium on Romance Languages, UrbanaChampaign, April 7-9, 1988, John Benjamins, Amsterdam, pp. 143-170.

- Caha, Pavel. 2009. The Nanosyntax of Case. PH.D. thesis, University of Thoms $\emptyset$.

- Chomsky, Noam. 1957. Syntactic Structures. The Hague: Mounton.

- -. 1980, On Binding, Linguistic Inquiry 11.1

- -. 1981. Lectures on Government and Binding. Dordrecht: Foris Publications.

- -. 1995. The Minimalist Program. Cambridge, MA: MIT Press.

- Company, Concepción.2003. Transitivity and Grammaticalization of object. The diachronic struggle of direct and indirect object in Spanish. In Romance objects: Transitivity I Romance Languages. Fiorentino, Jualiana (Ed.). Berlin: Mounton de Gruyter.

- Comrie, Bernard. 1976. Aspect. Cambridge: CUP

- -. 1989. Language Universals and Linguistic Typology. $2^{\text {nd }}$ ed. Oxford: Blackwell.

- Croft, William. 1990. Typology and universals. Cambridge: Cambridge University Press.

- Cuervo, María. 2003. Datives at Large. PH.D. thesis. MIT. 
- Demonte, Violeta. 1995. Dative alternation in Spanish. Probus 7.

- Dryer, Matthew. 1986. "Primary objects, secondary objects and antidative." Language 62.

- Fillmore, Charles J. 1968. The case for Case. In Universals in linguistic theory, Emmon Bach and Robert $T$ Harms (eds). New York NY: Holt, Rinehart and Winston.

- Haspelmath, Martin. 2005. "Ditransitive Constructions: The Verb 'Give'." In: Martin Haspelmath \& Matthew S. Dryer \& David Gil \& Bernard Comrie (eds.) The World Atlas of Language Structures. Oxford: Oxford University Press.

- -. 2007. Ditransitive alignment splits and inverse alignment. Functions of Language 14.

- -. 2015. "Ditransitive Constructions". To appear in Annual Review in Linguistics, vol. 1, 2015

- Hopper, Paul J. and Thompson, Sandra A. 1980. Transitivity in grammar and discourse. Language 56.

- -. 1982. Introduction. In Hopper and Thompson (Eds.)

- Jakobson, Roman. 1984. Beitrag zur allgemeinen kasuslehre: Gesamtbedeutung der russischen kasus. (translated as: General meanings of the Russian cases) [1936]. ed. Russian and SLavic grammar: Studies 1931-1981. Berlin: Mouton de Gruyter.

- Kittilä, Seppo. 2010. Transitivity Typology. In The Oxford Handbook of Linguistic Typology. Song, Jae Jung (Ed.)

- Larson, Richard. 1988. On the Double Object Construction. Linguistic Inquiry 19.

- Lema Labadie, José. 2015. Notas y lecturas en clase.

- Malchukov, Andrej and Comrie, Bernard and Haspelmath, Martin (eds.) 2010. Studies in ditransitive constructions: a comparative handbook. Berlin: De Gruyter Mounton. 
- Marantz, Alec. 1984. On the nature of Grammatical Relations. Cambridge, Mass.: MIT Press.

- Naess, Ashild. 2007. Prototypical Transitivity. In Typological Studies in Language 72.

- Pesetsky, David, and Esther Torrego. 2001. T-to-C movement: Causes and consequences. In Michael Kenstowicz, ed., Ken Hale: A life in language. Cambridge, Mass.: MIT Press.

- -. 2004. Tense, case, and the nature of syntactic categories. In Jacqueline Gueron and Jacqueline Lecarme, eds. The syntax of time. Cambridge, Mass.: MIT Press.

- Starke, Michal. 2005. Nanosyntax. Seminar taught at CASTL, University of Thoms $\emptyset$.

- Torrego, Esther. 1998. The dependencies of objects. Cambridge, Mass.: MIT Press. 


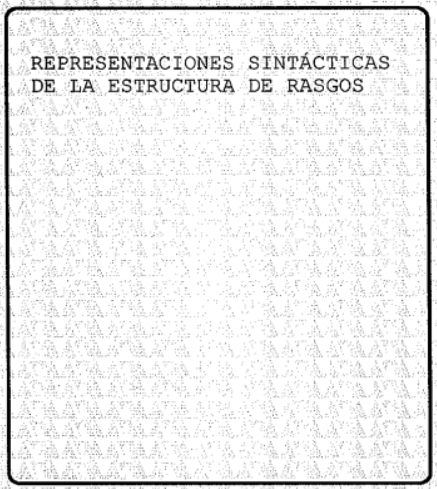

En la Ciudad de México, se presentaron a las 10:00 hora del día 23 del mes de enero del año 2017 en la Unidad Iztapalapa de la Universidad Autónoma Metropolitana, los suscritos miembros del jurado:

DRA. ANTOINETTE HAWAYEK GONZALEZ

R. JOSE LEMA LABADIE

DRA. MARIA ASELA REIG ALAMILLO

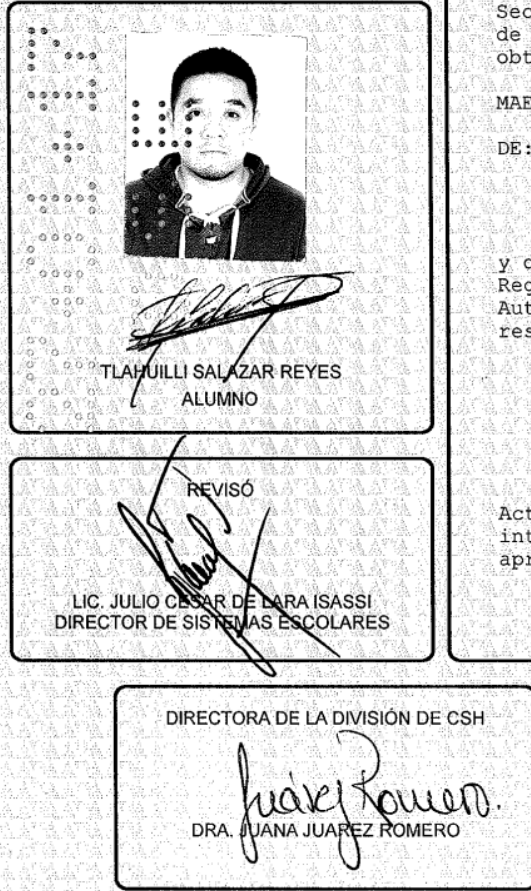

Bajo la Presidencia de la primera y con carácter de secretaria la última, se reunieron para proceder al Examen de Grado cuya denominación aparece al margen, para la obtención del grado de:

MAESTRO EN HUMANIDADES (LINGUISTICA)

DE: TLAHUILLI SALAZAR REYES

y de acuerdo con el artículo 78 fracción III del Reglamento de Estudios Superiores de la Universidad Autónoma Metropolitana, los miembros del jurado esolvieron

\section{Aprotodr}

cto continuo, la presidenta del jurado comunicó a interesado el resultado de la evaluación $y$, en caso aprobatorio, le fue tomada la protesta.

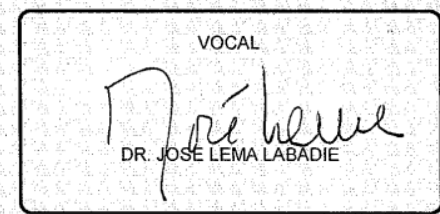

PRESIDENTA

lntorintte Llawayele

DRA. ANTOINETTE HAWAYEK GONZALEZ

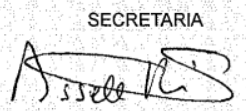

DRA. MARIAASELA REIG ALAMILLO 